\section{Latent learning impaired by REM sleep deprivation*}

\author{
CHESTER A. PEARLMAN, JR. \\ Boston V.A. Hospital, Boston, Mass. 02130
}

Stage REM sleep may be involved in some forms of learning. This hypothesis was examined by studying the effects of Stage REM deprivation in Blodgett's latent-learning situation. Stage REM deprivation blocked the appearance of the latent-learning effect, suggesting that adaptive coping of this sort is dependent upon Stage REM sleep.

The function of Stage REM sleep has remained enigmatic despite extensive research (Snyder, 1969). Indirect evidence has suggested that Stage REM (dreaming) involves the integration of past and present experience leading to effective coping (Breger, 1967; Greenberg, 1970; Pearlman, 1970). The simplest forms of coping, such as avoidance of a dangerous situation (Joy \& Prinz, 1969 ), could not be dependent upon Stage REM because this would be inconsistent with survival. The utilization of more complex bits of previous experience which have recently become important to the organism might involve Stage REM. As formulated by Dewan (1970) and Bryson \& Schacher (1969), reprogramming of this sort would interfere with the performance of existing programs if both were to occur simultaneously during waking. Thus, reprogramming could be accomplished efficiently during Stage REM. Retention of some types of learning is impaired by Stage REM deprivation (Fishbein, 1970; Leconte \& Bloch, 1970), consistent with this hypothesis.

Another experimental approach to this problem is provided by the latent-learning situation. Blodgett's (1929) classic study showed that rats given daily trials in a maze with no reward showed little reduction in blind alley (cul) entries and running speed, compared with animals which were rewarded following each completion of the maze. If the unrewarded animals were then given a reward on the fourth day, their performance on the following day improved markedly and was indistinguishable from that of

* The technical assistance of Michael Becker is gratefully acknowledged. the regularly rewarded animals. Blodgett concluded that the animals had acquired a latent knowledge of the maze during the unrewarded trials and that the great improvement resulted from integration of the reinforcement with this knowledge.

The present study consisted of two parts. First, Blodgett's procedure was replicated with interpolation of Stage REM deprivation between the rewarded trial and the trial on the following day. Then, an attempt was made to localize the effect of REM deprivation more precisely by confining the learning situation to a goalbox with no maze. The procedure of Tenen (1965) and Pinel (1969) was used, with interpolation of REM deprivation between the rewarded trial and the retention trial on the following day.

\section{METHOD}

Forty male albino rats, 3-4 months old, were placed on a 1-h/day feeding schedule and reduced to $90 \%$ of their original weights. After a week on the schedule, 32 were given one trial per day in a six-unit multiple-T-maze, identical to Blodgett's except for the absence of doors at choice points. Trials were run under $23 \mathrm{~h}$ of food

Table 1

Mean Values (Ranges in Parentheses) for Rewarded Trial and Test Trial (16 Animals in Each Group)

\begin{tabular}{|c|c|c|c|c|}
\hline & \multicolumn{2}{|c|}{ REM Deprived } & \multicolumn{2}{|c|}{ Stress Control } \\
\hline & Cul Entries & Time (Sec) & Cul Entries & Time (Sec) \\
\hline $\begin{array}{l}\text { Group mean on } \\
\text { fourth trial }\end{array}$ & $\begin{array}{c}7.2 \\
(1-37)\end{array}$ & $\begin{array}{c}115 \\
(42-517)\end{array}$ & $\begin{array}{c}10.1 \\
(1-39)\end{array}$ & $\begin{array}{c}206 \\
(27-637)\end{array}$ \\
\hline $\begin{array}{l}\text { Group mean } \\
\text { on fifth trial }\end{array}$ & $\begin{array}{c}7.8 \\
(2-17)\end{array}$ & $\begin{array}{c}137 \\
(25-383)\end{array}$ & $\begin{array}{c}6.1 \\
(1-26)\end{array}$ & $\begin{array}{c}119 \\
(21-612)\end{array}$ \\
\hline
\end{tabular}

Mean percentage improvement for each $\mathrm{S}$ between fourth and fifth trials $(65$ to -1100$) \quad(49$ to -463$)$ *Differs from stress control group $(p<.01)$ the $(95$ to -200$)$

$18 \%$

deprivation, and supplemental feeding was given an hour later. The number of cul entries and the time to traverse had not completed the maze in 15 min, it was removed. Thus, habituation to the maze was kept relatively equal for all animals. Twent They were equally divided between experimental and control groups. On the fourth day of training, the animals ound food in the goalbox for the first time. Following their supplementa feeding, 16 animals were deprived of (about $7 \mathrm{~cm}$ in diam) in a pool of water (Morden, Mitchell, \& Dement, 1967) until $3 \mathrm{~h}$ before the trial on the the day. EEG recordings of two deprivation of REM sleep by this technique was selective. Each animal had several REM periods of a few duration, which were abruptly interrupted by awakening or return to slow-wave sleep (total less $1 \%$ of time asleep). The amount observed under normal conditions (Duncan et al, 1968; Mouret, Pujol, \& Kiyona, 1969), suggesting that little of non-REM sleep had occurred. group for the stressful aspects of the REM-deprivation procedure. They were immersed in cool water for min to $1 \mathrm{~h}$ at varying intervals prio the trial on the fifth day. This the REM-deprivation procedure. The controls always became exhausted and co be removed from water to avoid drowning. They sufficiently to be able to run the maze. REM-deprived animals showed only the characteristic transient irritability and hyperactivity following remova the maze trial had elapsed f thents of spontaneous activity differ from baseline values. On the fifth day, both groups ran the maze to

(96 to -193$)$


Table 2

Mean Number of Explorations (Ranges in Parentheses) During Third Trial and Test Trial (Four Animals in Each Group)

\begin{tabular}{|c|c|c|}
\hline & $\begin{array}{c}\text { REM } \\
\text { Deprived }\end{array}$ & $\begin{array}{l}\text { Stress } \\
\text { Control }\end{array}$ \\
\hline $\begin{array}{l}\text { Group mean } \\
\text { of third trial }\end{array}$ & $\begin{array}{l}4.0 \\
(2-7)\end{array}$ & $\begin{array}{c}1.8 \\
(1-3)\end{array}$ \\
\hline $\begin{array}{l}\text { Group mean } \\
\text { of test trial }\end{array}$ & $\begin{array}{c}7.2 \\
(4-10)\end{array}$ & $\begin{array}{c}3.2 \\
(2-5)\end{array}$ \\
\hline $\begin{array}{l}\text { Mean percentage } \\
\text { increase for each } \\
S \text { between test trial } \\
\text { and third trial }\end{array}$ & $\begin{array}{c}98 \% \\
(43-166)\end{array}$ & $\begin{array}{c}110 \% \\
(0-200)\end{array}$ \\
\hline
\end{tabular}

an empty goalbox with wet food outside its walls.

In the second experiment, the eight remaining animals were given daily $5 \cdot \mathrm{min}$ trials in an apparatus like that of Pinel. It consisted of a box with a small niche in one wall. The number of times each animal explored the niche was recorded by a photoelectrically activated counter. The feeding schedule was similar to that of the first experiment. On the fourth day of training, the animals found food in the niche. Four animals were then REM-deprived, and four were given the stress control treatment. On the following day, the animals had another trial with an empty niche.

RESULTS

Most of the stress control animals showed the expected striking reduction in cul entries and running time on the fifth day. The performance of REM-deprived animals ranged from somewhat worse to slightly better than on the preceding day. For statistical evaluation, each animal was used as its own control. A measure of percentage improvement for each rat was calculated from the difference between performance on the fourth day and the fifth day divided by that on the fourth day. The Mann-Whitney U test showed the REM-deprived and stress-control groups to differ significantly in degree of reduction of cul entries $(p<.01)$ and of running time $(p<.01)$. Mean values for the two groups are shown in Table 1 .

In the Pinel box, however, REM-deprived and control groups showed an equal increase in number of niche explorations, compared to the day prior to the rewarded trial. Percentage increases, calculated as in the Blodgett experiment, showed no significant difference between the groups. Mean values appear in Table 2.

\section{DISCUSSION}

The results suggest that REM deprivation prevented integration of the unrewarded maze exploration with the reinforcement experience. The concept of integration is important because the results with the one-trial appetitive procedure indicate that REM deprivation produced no deficit in retention of information about the reinforcement.

An alternative interpretation of the effect of REM deprivation has been proposed by Albert, Cicala, \& Siegel (1970). They suggested that REM deprivation produces a drive state analogous to hunger, sensitizing the animal to environmental stimuli, with resultant increase in exploratory behavior. The one-trial appetitive procedure, however, showed no difference in exploratory behavior between REM-deprived and control animals. Some of my unpublished work has shown that 1 day of REM deprivation does not produce a significant increase in rate of barpressing for continuous food reward. Joy \& Prinz (1969) also failed to find an effect of REM deprivation upon simple conditioned avoidance learning. The increased rate of hypothalamic self-stimulation following REM deprivation found by Ellman \& Steiner (1969) might suggest some alternation in motivational state, but it seems likely that learned activities closely related to the rat's instinctive behavior are unaffected by REM deprivation. Thus, the REM state appears to operate at the more complex level involved in latent learning and two-way avoidance (Leconte \& Bloch, 1970).

Previous work with this REM-deprivation procedure has raised questions about whether the crucial variable is really $R E M$ deprivation or some nonspecific factor such as stress, fatigue due to total sleep loss, or hyperactivity following confinement upon the small pot (Leconte \& Bloch, 1970; Mark et al, 1969). An attempt was made to control each of these factors. A short period of REM deprivation was used. The control group underwent a stressful experience at least equal to that of the REM-deprived group. Non-REM sleep loss seemed minimal, and the hyperactivity of the REM-deprived animals had subsided before testing. The issue could be settled by studying animals following recovery from REM deprivation. This work is now in progress, and preliminary results confirm the findings of the present study.

REM sleep is associated with phenomena ranging from the fleeting, but fascinating, dream to the periodic peremptory activation of the sleeping brain appearing throughout the mammalian kingdom. The enigmatic quality of REM sleep has arisen, in part, from the difficulty of devising a theory to connect these differing phenomena. The idea of effective coping is such a psychophysiological bridge. The present data should be added to the evidence implicating REM sleep in the reorganizing and synthesizing activity of the brain (Oswald, 1969).

\section{REFERENCES}

ALBERT, I., CICALA, G. A.. \& SIEGEL, J. The behavioral effects of REM sleep deprivation in rats. Psychophysiology, $1970,6,550-560$.

BLODGETT, $H$. The effect of introduction of reward upon the maze performance of rats. University of California Publications in Psychology, 1929, 4, 113-134.

BREGER, L. Function of dreams. Journal of Abnormal Psychology Monographs, 1967, 72, No. 5, Pt. 2, 1-28.

BRYSON, D., \& SCHACHER, S. Behavioral analysis of mammalian sleep and learning. Perspectives in Biology \& Medicine, 1969 12. 71-79.

DEWAN, E. M. The programming ( $P$ ) hypothesis for REM sleep. International Psychiatry Clinics, 1970,7, Pt. 2 295-307.

DUNCAN, R., II, HENRY, P., KARADZIC V., MITCHELL, G., PIVIK, T., COHEN, H., \& DEMENT, W. Manipulation of the sleep-wakefulness cycle in the rat: A longitudinal study. Psychophysiology, $1968,4,379$.

ELLMAN, S. J., \& STEINER, S. S. The effect of REM deprivation on intracranial self-stimulation rates. Psychophy siology, $1969,6,237-238$.

FISHBEIN, W. Interferences with conversion of memory from short-term to long-term storage by partial sleep deprivation. Communications in Behavioral Biology (A), 1970, 5 171-175.

GREENBERG, R. Dreaming and memory International Psychiatry Clinics. 1970, 7 , Pt. 2, 258-267.

JOY, R. M., \& PRINZ, P. N. The effect of sleep altering environments upon the acquisition and retention of a conditioned avoidance response in the rat. Physiology \& Behavior, 1969. 4 , 809-814.

LECONTE, P. \& BLOCH, V. Déficit de la rétention d'un conditionnement après privation de sommeil paradoxal chez le rat. Comtes Rendus de l'Académie des Sciences de Paris, 1970, 271, 226-229.

MARK, J., HEINER, L. MANDEL, P., \& GODIN, $Y$. Norepinephrine turnover in brain and stress reactions in rats during paradoxical sleep deprivation. Life Science, 1969, 8, 1085-1093.

MORDEN, B.. MITCHELL, G., \& DEMENT, W. Selective REM sleep deprivation and compensation phenomena in the rat. Brain Research, $1967,5,339-349$

MOURET, J., PUJOL, J. F., \& KIYONO, S. Paradoxical sleep rebound in the rat. Effects of physical procedures involved in intracisternal injestion. Brain Research. $1969,15,501-506$.

OSWALD, I. Human brain protein, drugs and dreams. Nature, $1969,223,893-897$.

PEARLMAN, C. The adaptive function of dreaming. International Psychiatry Clinics, 1970, 7, Pt. 2, 329-334.

PINEL, J. P. A short gradient of ECS-produced amnesia in a one-trial appetitive learning situation. Journal of Comparative \& Physiological Psychology. $1969,68,650-655$.

SNYDER, F. Sleep and REM as biological enigmas. In A. Kales (Ed.), Sleep: Physiology and pathology. Philadelphia: Lipincott, 1969. Pp. 266-280.

TENEN, S. S. Retrograde amnesia from electroconvulsive shock in a one-trial appetitive learning task. Science, 1965 $148,1248-1250$ 